TAO, Vol. 15, No. 4, 667-681, November 2004

\title{
Multi-station Studies on Spread-F and VHF Scintillations in the Indian Sector
}

\author{
P. V. S. Rama Rao ${ }^{1, \star}$, D. S. V. V. D. Prasad ${ }^{1}$, K. Niranjan ${ }^{1}$, G. Uma ${ }^{1}$, \\ S. Gopi Krishna ${ }^{1}$ and K. Venkateswarlu ${ }^{1}$
}

(Manuscript received 20 March 2004, in final form 31 August 2004)

\begin{abstract}
A study carried out using ionospheric spread-F and VHF scintillation data of 1998 and 1999 I-STEP campaigns from a chain of five stations covering the equatorial and subtropical latitudes (geog. lat. $8^{\circ}$ to $23^{\circ} \mathrm{N}$ ) in the Indian sector indicates that the spread-F and scintillation activity can be classified into two broad categories (plasma bubble and BSS) depending on time duration of events and their onset at different latitudes. Recurrent short duration equatorial spread-F (ESF) and scintillation activity thought to be due to plasma depletions/bubbles are associated with a sharp F-region height rise at equatorial and subtropical latitudes. Such events are found to be more probable during equinox and winter solstice months, while the long duration events associated with the bottom side sinusoidal (BSS) irregularities are found to be less probable.
\end{abstract}

(Key words: Equatorial ionosphere, Ionospheric irregularities, Plasma depletions/bubbles )

\section{INTRODUCTION}

The occurrence of spread-F irregularities is a nighttime phenomenon, although at times irregularities may persist for a short period after sunrise. After sunset the F-layer usually rises upward rapidly. Spread-F often starts appearing within an hour or two after a local sunset and the time of onset and its maximum occurrence depends on the latitude of the location, season of the year and solar activity. Although the apparent connection between the rise of the F-layer and the appearance of spread-F was first noticed by Booker and Wells (1938), it has remained

\footnotetext{
${ }^{1}$ Department of Physics, Andhra University, Visakhapatnam, India

* Corresponding author address: Dr. P. V. S. Rama Rao, Department of Physics, Andhra University, Visakhapatnam, India; E-mail: palurirao@yahoo.com
} 
unexplained fully till today. A vast amount of data, mostly statistical in nature, has been gathered over the years from many parts of the globe. To a great extent, the statistical variation on the occurrence of spread-F is known in terms of local time and season, etc. It is also known quite well how the various radio propagational effects can arise if irregularities of electron density are present in the ionosphere. However, the most important aspect is to explain and forecast the generation of the irregularities themselves. This problem, although, has been understood to some extent, no satisfactory explanation has come out yet.

The occurrence of equatorial spread-F (ESF) on ionograms is in general correlated with the occurrence of amplitude scintillation of trans-ionospheric satellite signals. From the various radio wave propagation measurements, one can infer that various effects on the radio signal are caused by the irregularities of electron density, present across the ray path and aligned along the earth's magnetic field lines. It is known that the irregularities are generated over a wide range of altitudes, and different latitude regions. Ionograms show signatures of irregularities around the peak of the F-layer and below, while satellite measurements indicate the presence of irregularities even well above the peak of the F-layer as well. However, most of the amplitude scintillation effects seem to come from irregularities in the vicinity of the maximum of the F-layer.

Raghava Rao et al. (1988) made a comparative study of the changes in the latitudinal structure of the F-region electron density at fixed altitudes in the Indian equatorial region on days with and without post-sunset onset of equatorial spread-F using the ionosonde data of Ahmedabad, Waltair, and Kodaikanal. The enhancement of the electron density ratio prior to the onset of spread-F is interpreted as an intensification of the northern crest of the equatorial anomaly, with the ionization in the bottom side F-region as far north as $9^{\circ}$ from the dip equator participating in the crest intensification process. The role of the anomaly intensification at altitudes much below the F- region peak and associated neutral dynamics in the initiation of spread-F has also been studied.

Krishnamurthy (1993) made a review on the equatorial spread-F (ESF) using intense experimental and theoretical investigations in order to understand the generation and growth of spread-F irregularities which occur over a wide range of scale sizes. The instability mechanisms which are responsible for the growth of irregularities have also been discussed along with the relevant experimental observations. Further, it has been suggested that measurements of neutral wind and irregularity drifts are crucially important for understanding of the ESF irregularities especially in transitional and small-scale size regimes.

Sridharan et al. (1994) operated a day glow photometer at Waltair in a bi-directional mode, which revealed the features associated with the evolution of equatorial ionization anomaly (EIA) and its contribution to equatorial spread-F (ESF). It has also been reported that there exists a pre-cursor in the day glow that enables the prediction of ESF at least 3 hours prior to its actual occurrence.

Chandra et al. (1997) made a study on VHF scintillations and equatorial spread-F over SHAR during 1988 and reported that the occurrence of scintillations and spread-F is very high, with maximum hourly percentage occurrences of about $80 \%$ and $70 \%$ respectively. The spread-F started occurring slightly before $1900 \mathrm{hrs} \mathrm{LT}$ when scintillations in the satellite sig- 
nal also start appearing. On days with spread-F, h' $\mathrm{F}$ increases to about $400 \mathrm{~km}$ in the postsunset period, while on days without spread-F, h'F increases only to about $300 \mathrm{~km}$. It has also been reported that the vertical drift velocities exceeded $50 \mathrm{~m} \mathrm{~s}^{-1}$ on spread-F days in the postsunset period of sunspot maximum. During solar minimum spread-F occurs when the drift velocity exceeds $20 \mathrm{~m} \mathrm{~s}^{-1}$ (Basu et al. 1996).

Hysell (2000) made an overview and synthesis of plasma irregularities in equatorial spread-F (ESF) using the analysis of a satellite sounding rocket and coherent scatter radar observations. It was reported that three types of irregularities (bottom type, bottom side and top side) are found to occur, all of which are produced by ionospheric interchange instabilities. ESF is now known to be a manifestation of ionospheric interchange instabilities responding to the steep electron density gradient in the nighttime equatorial F-region of the ionosphere. These instabilities generate plasma density irregularities with scale sizes ranging from centimeters to hundreds of kilometers and relative amplitudes in excess of 99\%. The bottom type layers are composed of waves with wavelength of about $1 \mathrm{~km}$ while the bottom side irregularities can emerge when the F-region dynamo takes control of the flux tube. The top side irregularities can form when very strong polarization electric fields eject large regions of deeply depleted plasma through the peak of the F-region.

In the present investigation, the features of spread-F and scintillations in light of the above are studied from the Indian stations using spread-F data from Trivandrum (dip $0.6^{\circ} \mathrm{N}$ ), Kodaikanal (dip $\left.3.8^{\circ} \mathrm{N}\right)$, SHAR (dip $\left.10.8^{\circ} \mathrm{N}\right)$, Waltair $\left(\operatorname{dip} 20^{\circ} \mathrm{N}\right)$ and Ahmedabad (dip $33.8^{\circ} \mathrm{N}$ ) and scintillations data from Waltair during the increasing sunspot activity period of 1998 - 1999, and the results are reported.

\section{DATA}

Simultaneous amplitude scintillations data obtained at $244 \mathrm{MHz}$ from the FLEETSAT satellite signal at a low latitude station, Waltair during the period 1998 and 1999 are used in the present study. The elevation angle measured at Waltair from FLEETSAT is $66^{\circ}$ and the sub-ionospheric point is located at $16.4^{\circ} \mathrm{N}, 82.7^{\circ} \mathrm{E}$. Ionosonde data of spread-F and h' F obtained from Trivandrum, Kodaikanal, Sriharikota (SHAR), Waltair and Ahmedabad during the ISTEP campaign period (March, April 1998 and March, April 1999) is also made use of to monitor the dynamical behavior of the F-region ionosphere before the onset of spread-F and scintillations. The geographic locations of these stations are listed in Table 1 . The $10.7 \mathrm{~cm}$ solar flux variability during the period of observation was between 90 and 190 .

\section{RESULTS}

\subsection{Occurrence of Spread-F at the Different Locations}

With a view to make a comparative study on both range and frequency spread-F occurrence characteristics at four different locations namely, Trivandrum, SHAR, Waltair and Ahmedabad, the spread-F data are chosen and the average percentage occurrence of spread-F 
at all the stations during the ISTEP campaign period (16 - 30 April 1998) is computed and presented in Fig. 1. The peak percentage occurrence of spread-F is maximum (66\%) at the equatorial station, Trivandrum and decreased with the increasing dip latitude with $15 \%$ occurrence at Ahmedabad. The onset of spread-F is earlier (around $1900 \mathrm{hrs}$ IST) at Trivandrum and SHAR and later at Waltair and Ahmedabad. The peak percentage occurrence of spread-F was at $2100 \mathrm{hrs} \mathrm{IST}$ at Trivandrum, at $2200 \mathrm{hrs} \mathrm{IST}$ at SHAR, at $2230 \mathrm{hrs} \mathrm{IST}$ at Waltair, and at $2345 \mathrm{hrs} \mathrm{IST}$ at Ahmedabad. Interestingly enough, it is seen that post-midnight spread-F is present till pre-dawn hours ( $0500 \mathrm{hrs}$ IST) at all stations except at the farthest station, Ahmedabad during the present period of observation. From earlier studies made at Waltair, Rama Rao et al. $(1992,1996)$ and Sriram (1993) reported that the probability of spread-F occurrence during high solar activity period is maximum at equatorial station, Trivandrum with almost $100 \%$ occurrence while it decreases towards sub-tropical latitudes with $75 \%$ occurrence at Waltair.

The occurrence of scintillations with peak amplitudes $\geq 3 \mathrm{~dB}$ is considered for every $15 \mathrm{~min}$. intervals in the present study. The durations of nighttime spread-F at five ionosonde stations and scintillations at Waltair for most of the nights of observation during the ISTEP campaign

Table 1. Locations of Ionosonde and VHF Scintillation Recording Stations.

\begin{tabular}{|l|c|c|c|c|}
\hline $\begin{array}{c}\text { Name of the } \\
\text { Station }\end{array}$ & $\begin{array}{c}\text { Parameter } \\
\text { Measured }\end{array}$ & \multicolumn{2}{|c|}{ Geographic coordinates } & Dip $\left({ }^{0} \mathbf{N}\right)$ \\
\hline & & Lat. $\left.{ }^{0} \mathbf{N}\right)$ & Long. $\left({ }^{0} \mathbf{E}\right)$ & \\
Trivandrum & Spread-F & 8.3 & 76.9 & 0.6 \\
Kodaikanal & Spread-F & 10.2 & 77.5 & 3.5 \\
Sriharikota & Spread-F & 13.7 & 80.2 & 10.8 \\
(SHAR) & Scintillations & 17.7 & 83.3 & 20 \\
Waltair & $\&$ spread-F & & & 33.8 \\
\hline
\end{tabular}


period of March 1998 are presented in Fig. 2. It is seen from this figure that spread-F and scintillations occurred during both pre- and post-midnight hours at almost all the five stations (except for a few days at Ahmedabad). At the equatorial stations (Trivandrum and Kodaikanal), the spread-F was found to occur continuously over longer periods, whereas at latitudes away from the equator like Waltair, spread-F and scintillation activity appeared as recurrent short duration events with varying time durations. At the intermediate latitude (SHAR), the spreadF occurrence showed almost similar long duration features as those of the equatorial station. It is reported (Woodman and Lahoz 1976) that Jicamarca radar plumes show that at high lati-

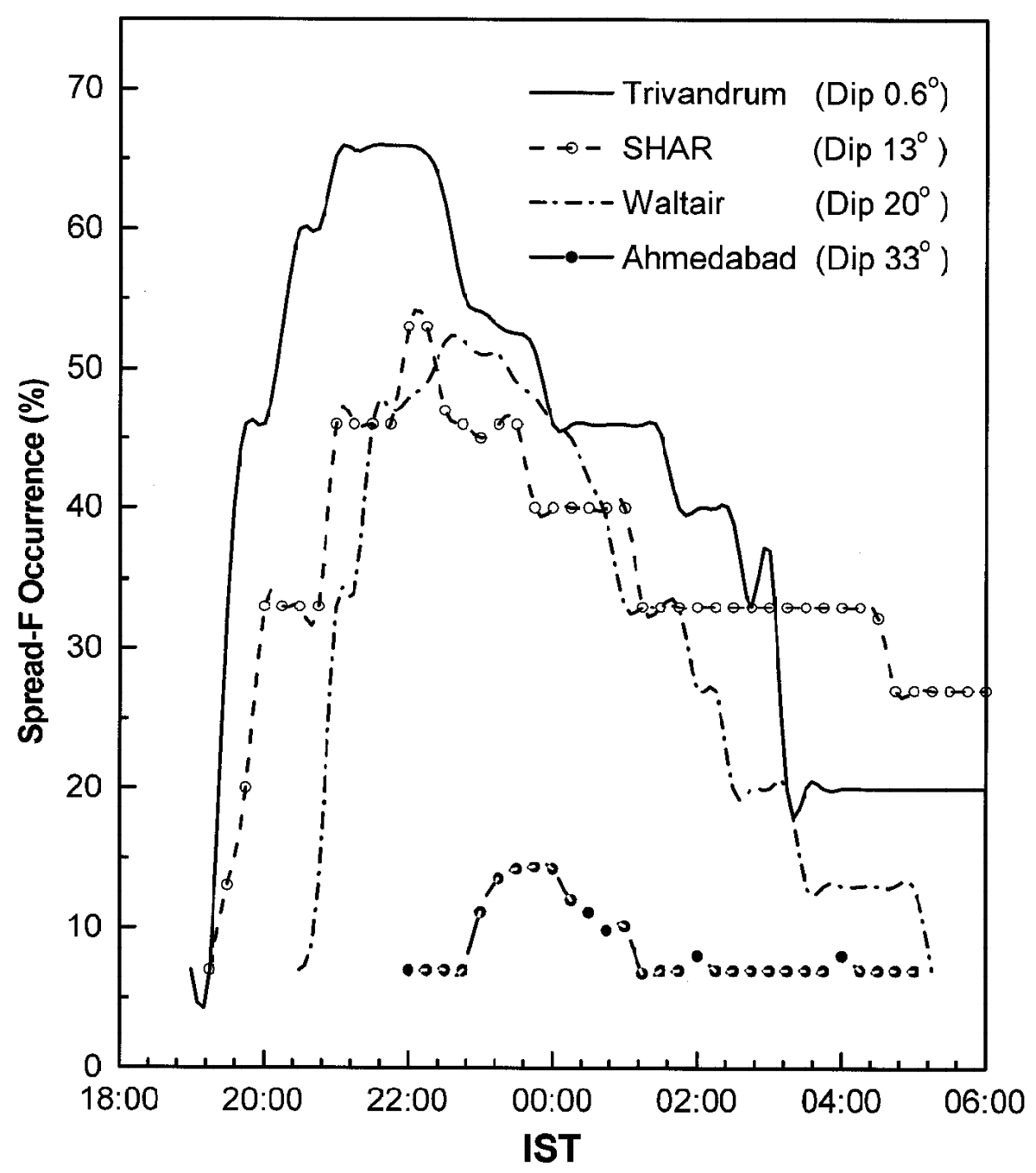

Fig. 1. Nocturnal variation of the percent occurrence of spread-F at four Indian stations during 16 - 30 April 1998. 
tudes the plumes are well separated. The high altitude discrete plumes map along the magnetic field lines to higher magnetic latitudes where the spread-F structure becomes more discrete. Figure 3 shows the distribution of short and long duration events of spread-F at different stations (including scintillation events at Waltair) indicating the higher probability of occur-

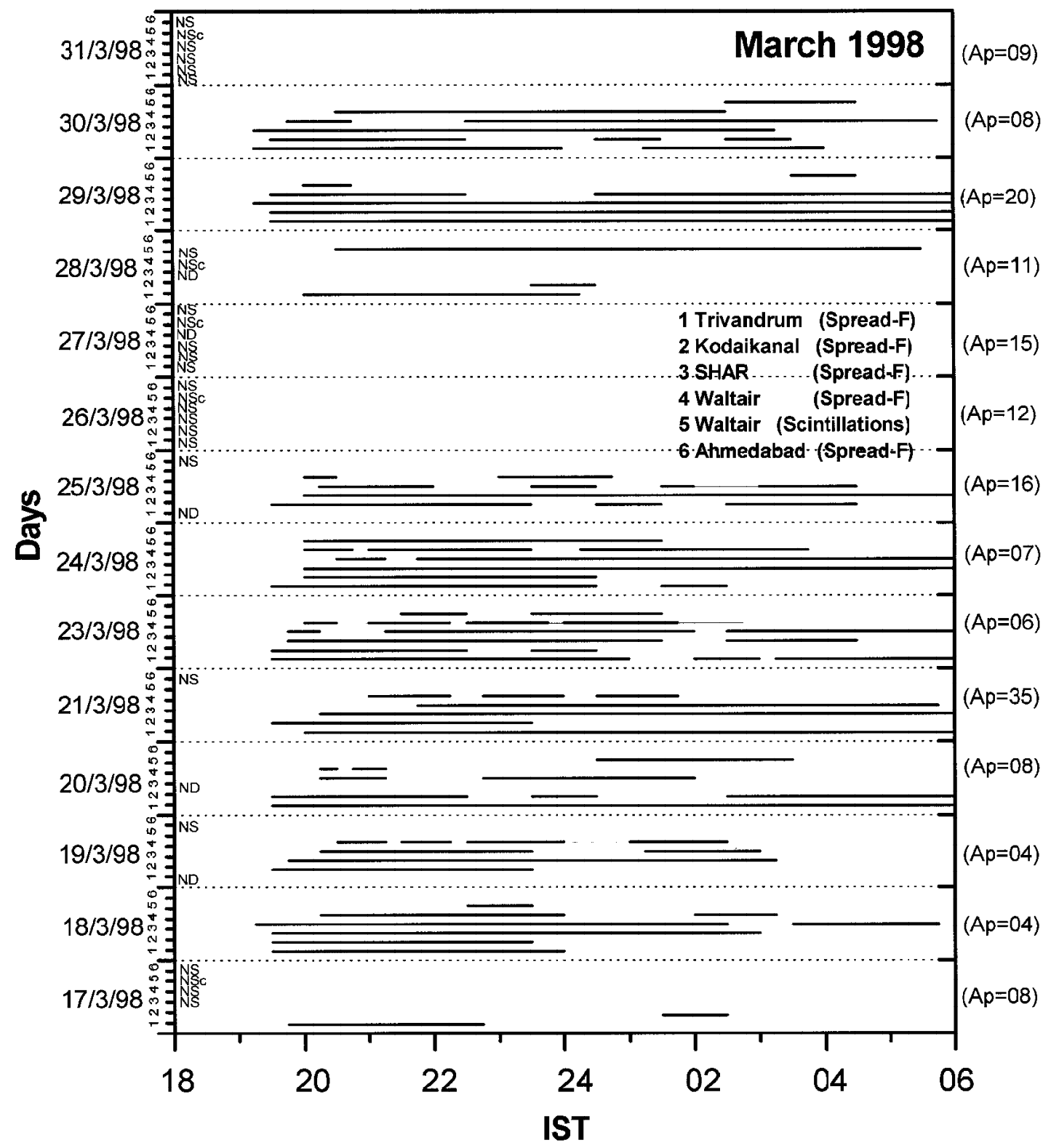

Fig. 2. Plot showing the presence of spread-F and scintillations as a function of time at different stations during 17 - 31 March 1998. 
rence of short duration events away from the equator.

Somayajulu et al. (1984) and Nelson et al. (1985) reported that the detection of spread-F events in low latitude ionograms is possible only during a rising plasma bubble event.

Basu et al. (1990) reported that discrete scintillation patches are observed to be associated with bubbles, while continuous scintillation events existing for over five hours duration are associated with Bottom Side Sinusoidal (BSS) irregularities. It has also been reported that the frequency of occurrence of BSS irregularities at Huancayo $\left(12^{\circ} \mathrm{S}\right)$ maximizes at solstices and has a longitudinal distribution that depends on the season and that the BSS irregularities are observed more frequently in the local summer at low latitudes. In the present data, the total

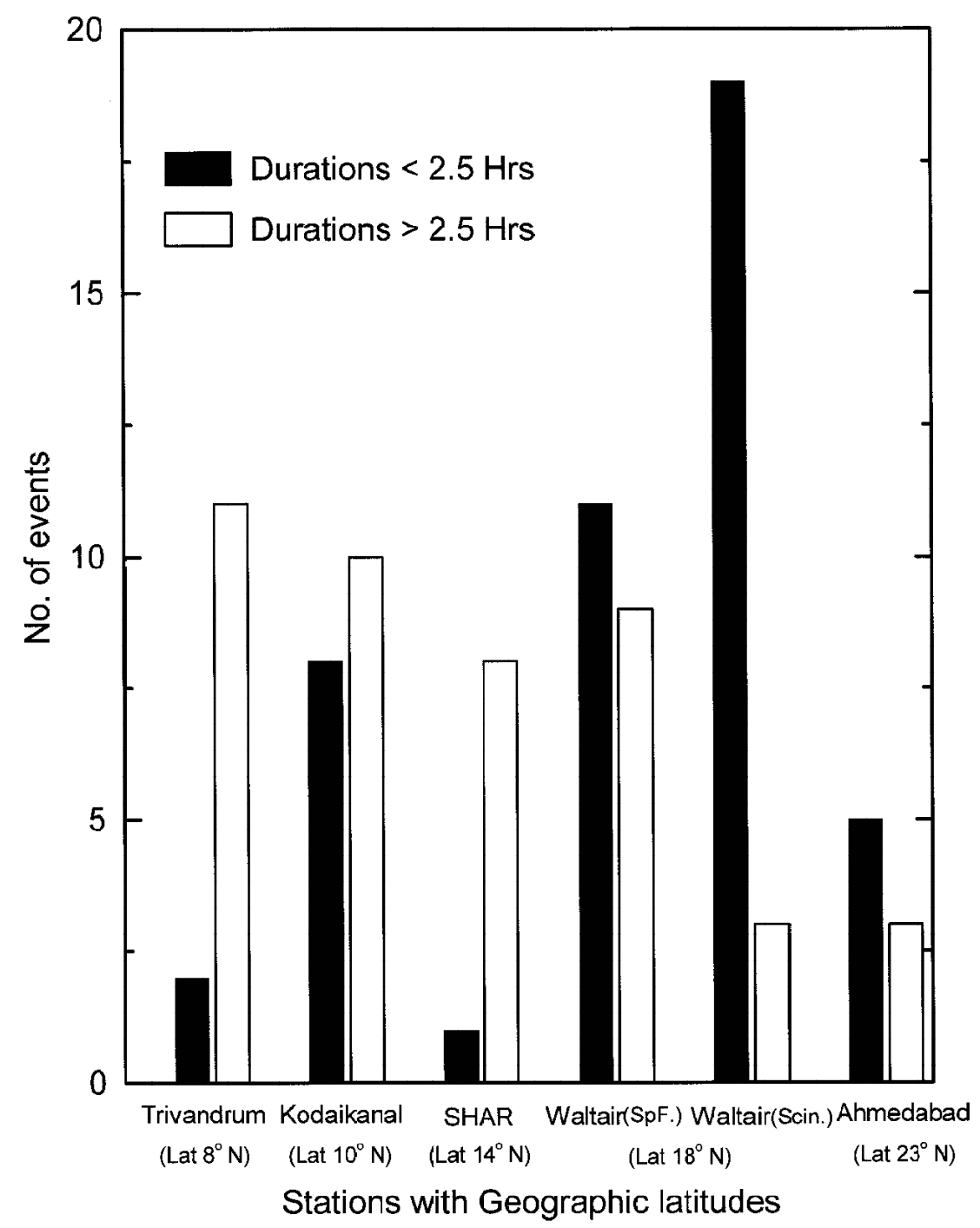

Fig. 3. Time Distribution of spread-F events at different stations. 
number of scintillation patches observed are 21. Only one scintillation patch with a long duration $(>2.5 \mathrm{hrs})$ is observed at Waltair while the number of short duration $(\leq 2.5 \mathrm{hrs})$ patches are twenty. Therefore, on the assumption of the association of short duration scintillation patches with plasma bubbles and long duration scintillations with BSS irregularities (Basu et al. 1990), it may be inferred that at Waltair during increasing solar activity conditions, the occurrence of scintillations due to plasma bubbles is maximum and those corresponding to BSS type are rare (Fig. 3).

\subsection{Association of Virtual Height of F-layer (h'F) Variations in the Occurrence of Scintillation Patches}

The criterion on layer height and pre-reversal vertical velocity enhancement will be different for generation and growth of the plasma bubble induced spread-F irregularities as opposed to bottom side spread-F irregularities (Nelson et al. 1985). The dependence of long duration scintillation patch occurrences at Waltair during different seasons is compared with the seasonal average of vertical drift variations in the height of the F-layer (dh'F/dt) and presented in Fig. 4. The maximum occurrence of short duration patches seen at the equinox and winter solstice may be explained on the basis of a sharp rise and fall of F-layer altitude and consequent large variations in dh' F/dt as seen from Fig. 4. Further, the vertical drift during such nights was found to show large upward/ downward movement within a night. The nocturnal h'F variations during the occurrence of typical short and long duration patches of scintillations are presented in Fig. 5. On the 24 March 1998, the F-layer is suddenly elevated from $250 \mathrm{~km}$ to $325 \mathrm{~km}$ between 18:00 and 19:00 hrs and the scintillation onset was seen from 19:15 hrs IST. This scintillation onset was followed by patchy events with three discrete patches. In contrast, on the 30 March 1998 (Fig. 5), sudden increase in the height of the F-layer during the post sunset period was not present and scintillation activity started by 20:30 hrs and continued till 02:30 hrs of the following day i.e., the activity was characterized by a single long duration patch of about 6hrs duration. This feature is studied on a day-to-day basis, and it is observed that the post sunset peak values of h'F are higher when short duration patches (attributed to plasma bubble type irregularities) are observed, than the peak values of h'F during the occurrence of long duration patches of scintillations (BSS irregularities). Thus at Waltair, the short duration scintillation activity believed to be associated with plasma bubble type irregularities is preceded by a sharp rise in the F-layer altitude, while the long duration BSS type irregularities do not seem to be associated with such sudden altitude rise of the Flayer during post-sunset hours. This feature is in agreement with the earlier results reported by Somayajulu et al. (1984).

\subsection{Multi-Station Studies of h'F Variations During Spread-F and Non Spread-F Conditions}

The h'F data used in this study is from a chain of four ionosonde stations, Trivandrum, Kodaikanal, Waltair and Ahmedabad in the Indian sector operated during the ISTEP cam- 
paign periods of March 17 - 31, 1998 \& April 5 - 20, 1999. The nocturnal variation of minimum virtual heights ( $h^{\prime} F$ ) from all the four ionosonde stations on a typical night of 10 March, with no spread-F occurrence is presented in Fig. 6a along with another typical night of 19 March with the presence of spread-F at all the four stations in Fig. 6b. When spread-F is present (Fig. 6b), the post-sunset h' $F$ variations show a steep rise and fall in the F-layer height followed by a rather smooth variation in h'F during the later part of the night. On the spread$\mathrm{F}$ day, the F-layer ascent is highest at the equatorial stations ( $400 \mathrm{~km}$ at Trivandrum and 375 at

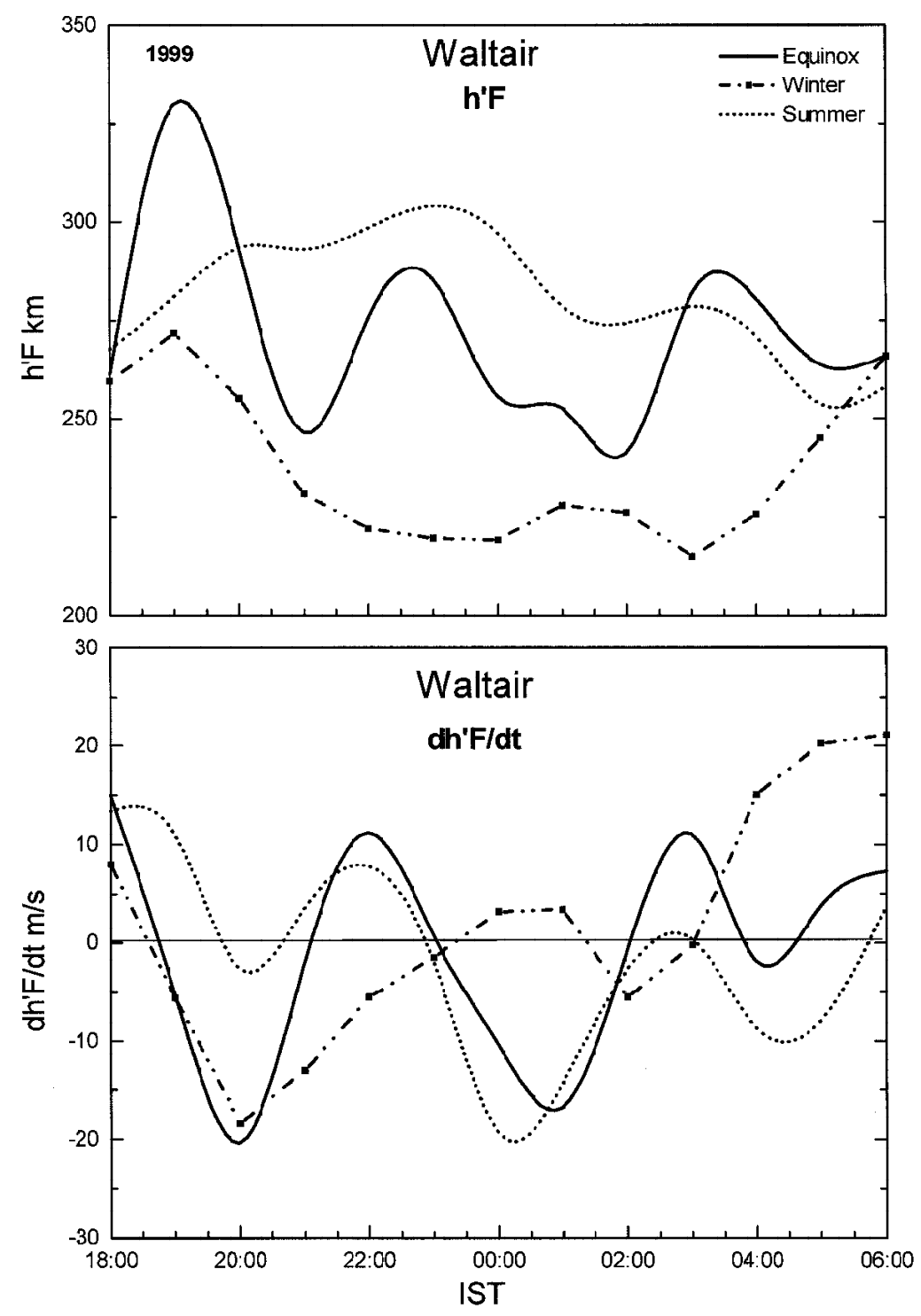

Fig. 4. Nocturnal variation of h'F (top panel) and vertical drift (dh' F/dt - bottom panel) at Waltair during different seasons of 1999. 

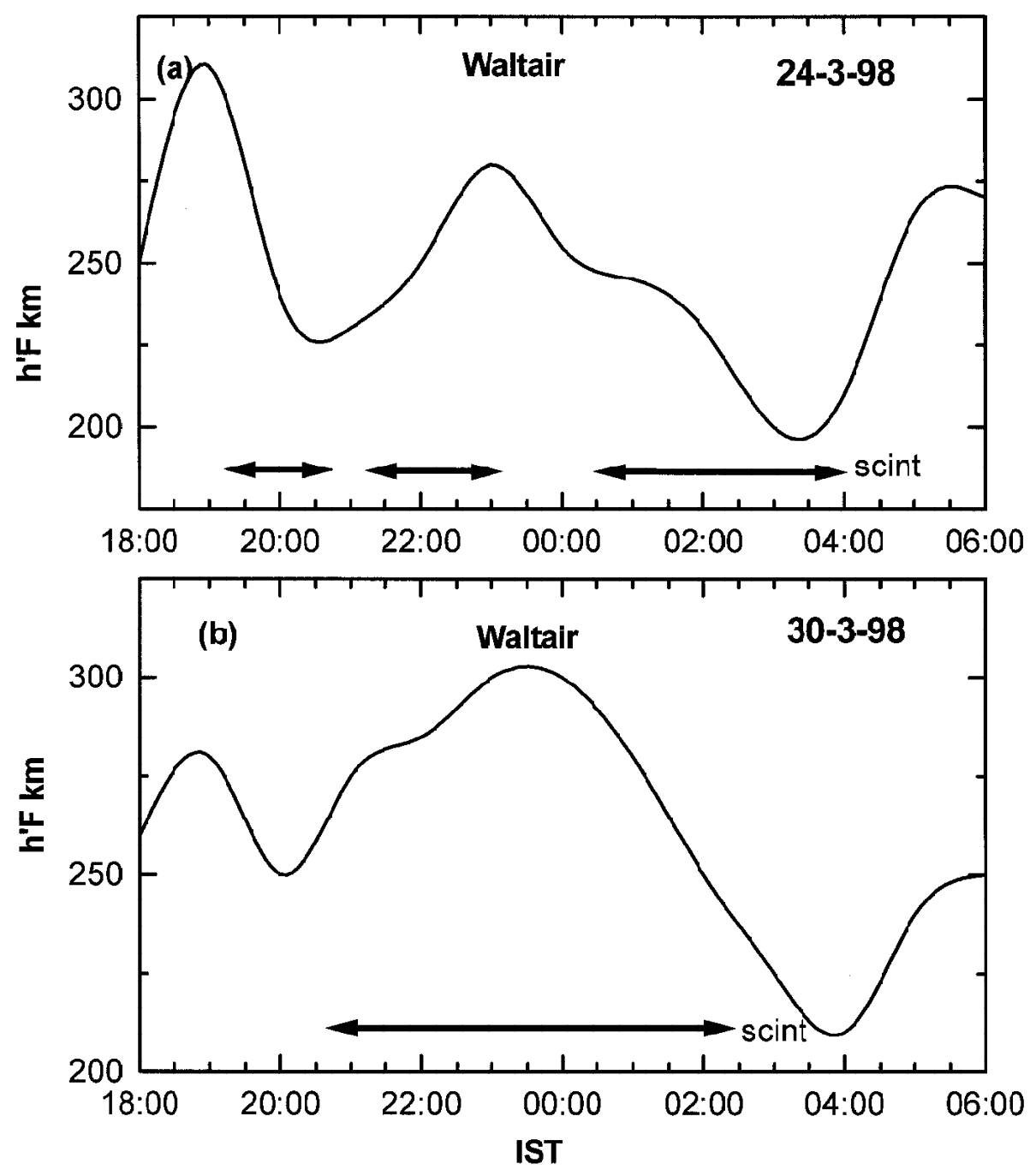

Fig. 5. h'F variations during short and long duration patch occurrences of scintillations.

Kodaikanal) and lower at off-equatorial stations, Waltair $(325 \mathrm{~km})$ and Ahmedabad $(275 \mathrm{~km})$.

It is known that two types of spread-F irregularities (plasma bubbles and BSS) are identified from their onset time delays and durations, at stations with different longitudes and latitudes (Tsunoda et al. 1982; Somayajulu et al. 1984; Dabas and Reddy 1986). If the spread-F occurrence at the three equatorial and low latitude stations (Trivandrum, SHAR, Waltair) were due to rising plasma bubbles, then the time delays between the onset of spread-F at the three stations should vary between 5 and $15 \mathrm{~min}$. (Dabas and Reddy 1986). Hence, in the present study, if the onset of spread-F at Trivandrum and SHAR occurs at the same time or with a time 
delay of less than $15 \mathrm{~min}$, then those spread-F irregularities are considered to be due to the rising plasma bubbles. With a view to study this aspect, the h'F variations during spread-F and no spread-F conditions, two typical nights (20 March 1999 and 5 April 1999) are chosen, because on 20 March, spread-F occurred at all the three stations, while on 5 April, spread-F occurred only at Trivandrum. These h' $\mathrm{F}$ variations along with spread-F occurrences are presented in Fig. 7. The peak values of h'F on 20 March at Trivandrum, Waltair and Ahmedabad are nearly 350, 310, and $280 \mathrm{~km}$ respectively while on 5th April, the peak h'F values are 350,

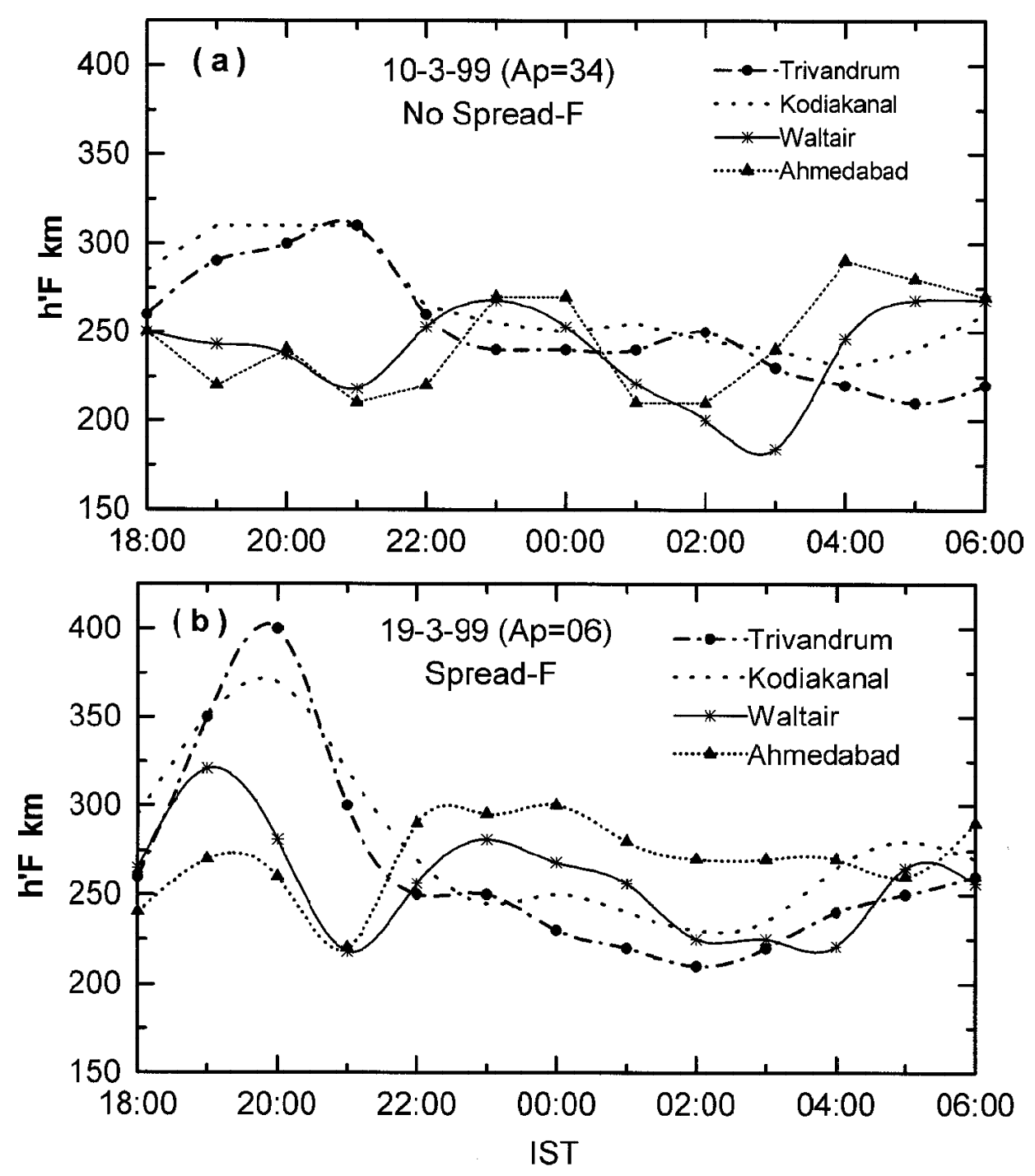

Fig. 6. Nocturnal variations of h' $\mathrm{F}$ at four different stations during non-spread $\mathrm{F}$ (top panel) and spread-F (bottom panel) nights. 
280 and $250 \mathrm{~km}$ respectively at the above three stations. The difference in the peak values of h' $\mathrm{F}$ at Waltair and Ahmedabad might have contributed to the occurrence and non-occurrence of spread-F at Waltair and Ahmedabad on 20 March and 5 April 1999 respectively.

Similarly, on 29 March (Fig. 2), the spread-F occurred first at SHAR followed by the occurrence at Trivandrum and the duration of this patch is found to be large (about $10 \mathrm{hrs)}$ ) at both the stations. On this day, a small (30 min. duration) scintillation patch is observed at Waltair. This feature may be attributed to BSS irregularities, basing on the long duration nature of spread-F at SHAR and Trivandrum and also its prior occurrence at SHAR. The scanty occurrence of scintillations at Waltair could be due to the extension (Geomagnetic Lat. $6.4^{\circ} \mathrm{N}$ ) of irregularity belt boundary, because it is reported that the belt extends up to $9^{\circ}$ geomagnetic latitude during high sunspot conditions (Pathan et al. 1992). Since the scintillations or spread$\mathrm{F}$ are first observed on an eastern station (scintillations at Waltair and spread-F at SHAR and Trivandrum), the movement of irregularities appears to be westward in the initial stages of their onset. However, the terminator (sunset line) moves westward and causes the onset of irregularities to occur first in the east and then in the west. Therefore, it may appear as a westward movement of irregularity structures in the initial stages but may not be so all the time. In addition to the differences in the onset of spread-F, the irregularities observed on this day can be inferred as BSS irregularities on the basis of h'F variations (Fig. 8), which showed broad peaks at Trivandrum and SHAR, and a relatively sharp post-sunset peak at Waltair. Since broad peaks with slow rate of increase in nocturnal h' $F$ variations are considered to be causes of BSS irregularities, the occurrence of spread-F and scintillations discussed above may be attributed to BSS type irregularities.

\section{SUMMARY}

The occurrence and onset of spread-F at equatorial stations is both maximal and earlier. With increasing latitude, percent occurrence decreases and onset times are also delayed. Events of spread-F/scintillations preceded by sharp rises and falls in F-region altitudes were found to be of recurrent short duration type resembling the irregularities associated with rising plasma bubbles. Long duration spread-F/scintillations events are not necessarily preceded by large elevations of the F-layer and resemble irregularities due to bottom side sinusoidal (BSS) perturbations. Recurrent short duration ESF events are found to be more frequent, while long duration events associated with BSS type of irregularities are less frequent during equinox and winter solstice months at equatorial and sub-tropical latitudes in the Indian sector.

Acknowledgements The authors wish to express their sincere thanks to Prof. J. H. Sastri, Indian Institute of Astrophysics, Bangalore, Prof. Harish Chandra, Physical Research Laboratory, Ahmedabad and Prof. V. V. Somayajulu, Vikram Sarabhai Space Center, Trivandrum for providing the ionosonde data. The authors are grateful to the Department of Science and Technology (DST), Govt. of India for providing a project under AICPITS. One of the authors (PVS) is grateful to Council of Scientific \& Industrial Research (CSIR), Govt. of India for providing him with an Emeritus Scientist project. Authors are grateful to Dr. Santimay Basu and the other reviewer for their valuable comments and suggestions. 


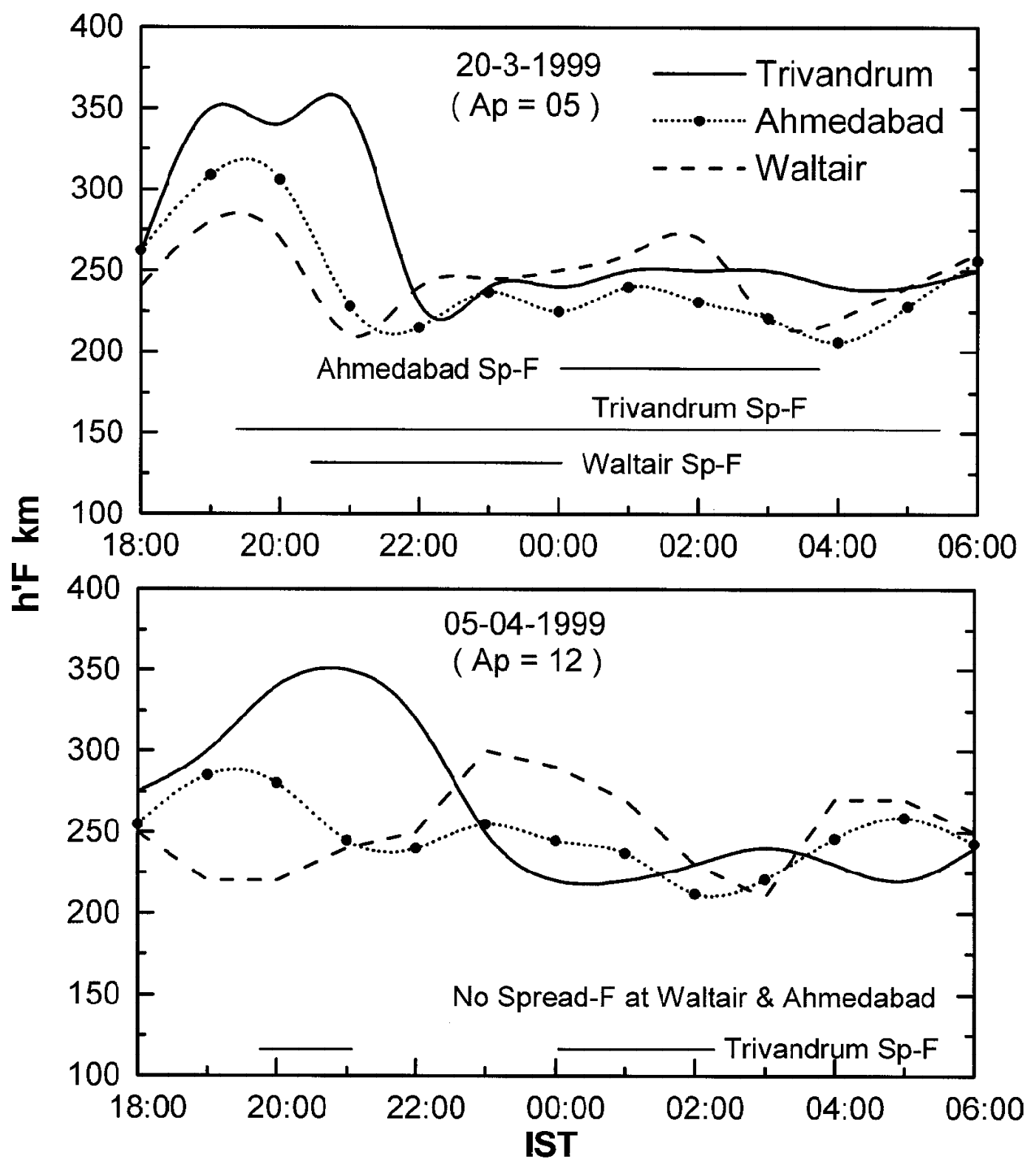

Fig. 7. Nocturnal variation of h' $\mathrm{F}$ at three different stations for different durations of spread-F. 


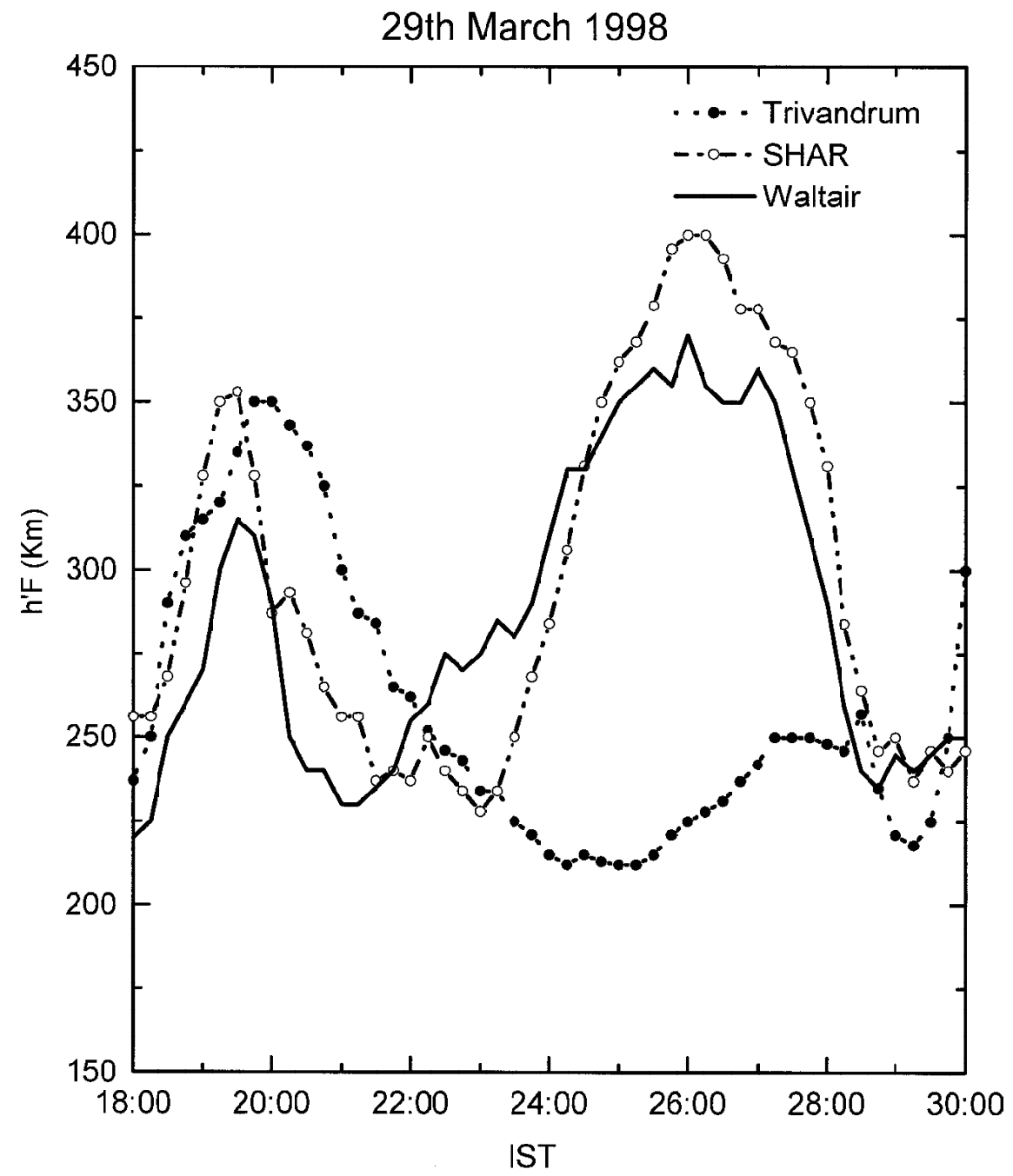

Fig. 8. Nocturnal variation of h' F at three different stations on 29 March 1998.

\section{REFERENCES}

Basu S., C. E. Valladares, S. U. Basu, W. B. Hanson, E. Kudeki, W. E. Swartz, and R. F. Woodman, 1990: Multi technique irregularity and drift measurements near Jicamarca. Inter. Symp. Equatorial Aeronomy, 191-199.

Basu S., E. Kudeki, Su Basu, C. E. Valladares, E. J. Weber, H. P. Zengingonul, S. Bhattacharya, R. Sheehan, J. W. Meriwether, M. A. Biondi, H. Kuenzler, and J. Espinoza, 1996: Scintillations, plasma drifts and neutral winds in the equatorial ionosphere after sunset. J. Geophys. Res., 101, 26795-26809. 
Booker, H. G., and H. G. Wells, 1938: Scattering of radio waves in the F-region of ionosphere. Terr. Mag. Atmos. Elec., 43, 249-256.

Chandra, H., G. D. Vyas, H. S. S. Sinha, S. Prakash, and R. N. Misra, 1997: Equatorial spread-F campaign over SHAR. J. Atmos. Terr. Phys., 59, 191-205.

Dabas, R. S., and B. M. Reddy, 1986: Nighttime VHF scintillations at $23^{\circ} \mathrm{N}$ magnetic latitude and their association with equatorial F-region irregularities. Rad. Sci., 21, 453-462.

Hysell, D. L, 2000: An overview and synthesis of plasma irregularities in equatorial spread-F.J. Atmos. Sol. Terr. Phys., 62, 1037-1056.

Krishna Murthy, B. V, 1993: Equatorial spread-F. Indian J. Radio Space Phys., 22, 82-88.

Nelson, O. R., M. A. Abdu, and I. S. Batista, 1985: Equatorial F-region irregularity latitudinal extension and dynamo electric field. J. Atmos. Terr. Phys., 48, 181-186.

Pathan, B. M., R. G. Rastogi, and D. R. K. Rao, 1992: On the width and complexities of the equatorial nighttime radio wave scintillation belt in the Indian region. J. Geomag. Geoelect., 44, 129-142.

Raghava Rao, R., M. N. Rao, J. H. Sastri, G. D. Vyas, and M. S. R. Rao, 1988: Role of equatorial ionisation anomaly in the initiation of equatorial spread-F.J. Geophys. Res., 13, 5959-5964.

Rama Rao, P. V. S., D. S. V. V. D. Prasad, P. Sriram, and P. T. Jayachandran, 1992: Multistation studies of VHF scintillations from equator to low latitudes.Proc. Inter. Bea. Sat. Symp., Boston, USA, 88.

Rama Rao, P. V. S., P. Sri Ram, P. T. Jayachandran, and D. S. V. V. D. Prasad, 1996: Multistation VHF scintillation studies at low latitudes. Planet. Space Sci., 44, 12091217.

Somayajulu, Y. V., S. C. Garg, R. S. Dabas, L. Singh, T. R. Tyagi, B. Lokanadham, S. Ramakrishna, and G. Navneeth, 1984: Multistation study of nighttime scintillations in low latitudes : Evidence of control by equatorial F-region irregularities.Rad. Sci., 19, 707-718.

Sridharan, R., D. P. Raju, R. Raghava Rao, and P. V. S. Rama Rao,1994: Precursor to equatorial spread-F in OI $630.0 \mathrm{~nm}$ dayglow. Geophys. Res. Letts., 21, 2797-2800.

Sriram, P, 1993: Equatorial and low latitude ionospheric phenomena as observed from the satellite beacon \& ionosonde measurements, Ph.D. Thesis, Andhra University, India.

Tsunoda, R. T., R. C. Livingston, J. P. McClure, and W. B. Hauson, 1982: Equatorial plasma bubbles: Vertically elongated wedges from the bottom side F-layer.J. Geophys. Res., 87, 9171-9180.

Woodman R. F., and C. Lahoz, 1976: Radar observations of F-region equatorial irregularities. J. Geophys. Res., 81, 5447-5466. 